\title{
Las relaciones sexuales, encuesta a los estudiantes de la Universi- tat Pompeu Fabra, Barcelona (20 a 27 años)
}

\section{Sex Survey about university students of UPF (from 20 to 27 years old)}

\author{
Carmen Maté ${ }^{1}$, Nolasc Acarín \\ Agencia de Ecología Urbana de Barcelona \\ Barcelona, España \\ (Recepción: Enero 2010 - Aceptación: Septiembre 2010)
}

\begin{abstract}
Resumen
El propósito de la encuesta sobre sexualidad es valorar las actitudes, las prácticas y el nivel de conocimientos de los universitarios de entre 20 a 27 años e identificar si hay diferencias por la edad y la actividad sexual en comparación con otras encuestas. El estudio comprende una muestra de 838 estudiantes que realizaban tercero o cuarto curso de Humanidades. Las diferencias de las respuestas entre hombres y mujeres se testaron con la $\chi^{2}$ de Pearson. El estudio establece qué conducta, conocimientos, actitudes y prácticas varían en función del sexo. La edad de las primeras relaciones sexuales está alrededor de los 15,4 años y no se obtienen diferencias estadísticamente significativas entre ambos sexos. El despertar del interés sexual se produce a los 13,5 años, pero se obtienen diferencias estadísticamente significativas entre los sexos, en los varones es de 12,7 y en las mujeres de 13,7 años. Los estudiantes que se declaran sexualmente activos manifiestan que sus relaciones son satisfactorias e importantes para su equilibrio personal. Mayoritariamente manifiestan haber utilizado métodos anticonceptivos en su última relación y en la misma proporción afirman utilizar preservativos como medio para evitar la transmisión de ETS. Hay un $21 \%$ de los universitarios que no utiliza ningún medio para evitar las ETS. Nuestra conclusión es que tanto el conocimiento como las actitudes de los estudiantes requieren programas de educación sexual en los estudios de secundaria.
\end{abstract}

Palabras claves: inicio relaciones sexuales, contracepción, enfermedades de transmisión sexual.

\begin{abstract}
The purpose of the present survey was to assess the level of sexual knowledge, attitudes and practice of university students, adult young people from 20 to 27 years old and to identify if there was any significant difference in terms of age and sexual activity with other surveys. The survey was undertaken in which data were collected from 838 students who attended the third and four course of their graduate in Humanities. Differences between answers by sex were tested using Pearson's $\chi^{2}$ test. The study established that behaviour, knowledge, attitudes and practice of the universitary students vary by sex in some regards. The first sexual relationships is around they have 15,4 years old and no statistically significant difference was found between sex. The average of the starter interesting about sex is around 13,5 years old and a statistically significant difference was found between sex, the average of boys is 12,7 years old and girls 13,7. People who were sexually active are satisfied and show is so important to their wellbeing. Majority use contraceptive methods in the last relationship and the same percentage use the condom in order to avoid sexually transmitted diseases. The study confirmed that there are $21 \%$ the students don't use any method to avoid sexually transmitted diseases. Our conclusion is both, the knowledge and attitudes of students necessarily required appropriate sex education in the secondary school.
\end{abstract}

Key words: starter sex relationships, contraceptives, sexually transmitted diseases.

1 Correspondencia a: Carmen Maté. Jefe de Proyectos de la Agencia de Ecología Urbana c/Escar nº 1, $3^{\circ} 08039$ Barcelona, España. E-mails: carme.mate@upf.edu, carmenmate@bcnecologia.net. 


\section{Introducción}

El proyecto de estudio surgió al leer los datos publicados por Demoscopia en 1997 (publicada en EL PAÍS 23 marzo 1997) sobre una encuesta de ámbito nacional, realizada a 4000 estudiantes universitarios. Las preguntas se centraban en aspectos de la conducta sexual de nuestra especie, tema que formaba parte de los contenidos curriculares de las dos asignaturas que impartían los autores. El formulario contenía algunas preguntas similares para poder compararlas, no obstante planteamos otras para conocer aspectos concretos de la conducta sexual como las fases de la seducción, los valores que seleccionan en su pareja para tener una relación estable frente a una fugaz o la edad del despertar el interés por la sexualidad, a valorar la información que disponen sobre enfermedades de transmisión sexual, entre otras. Así el cuestionario constaba de 42 preguntas con formatos diversos, en algunas las respuestas eran dicotómicas, otras a elegir entre varios caracteres y priorizar, o bien seleccionar. No obstante la mayoría eran de respuesta única y cerrada. Por cada bloque temático había más de 10 preguntas pero en el cuestionario no se presentaban agrupadas. En este trabajo se analizan quince preguntas sobre el inicio de las relaciones sexuales y la información que disponen sobre métodos anticonceptivos y profilácticos.

En este estudio se presentan dos aspectos básicos de la conducta sexual. El primero es conocer el inicio de las relaciones sexuales y la tipología de las mismas, así como el despertar del interés sexual, la importancia que los universitarios otorgan a las relaciones sexuales y si tienen, o no, preferencia horaria. El segundo es poder valorar el efecto que tienen los programas de educación sexual impartidos en secundaria sobre el uso de métodos anticonceptivos, conocimientos sobre el SIDA y las enfermedades de transmisión sexual. Se comparan los resultados obtenidos con otras encuestas similares realizadas en otros países, procurando que la muestra corresponda al mismo intervalo de edad aunque lógicamente existirán diferencias culturales, sociales e incluso de homogeneidad de las muestras.

La mayor parte de los datos disponibles acerca de las actitudes y comportamientos sexuales proviene de las investigaciones realizadas en EEUU. No obstante, la expresión sexual en otras sociedades ha captado el interés de diversas disciplinas y sus descubrimientos proporcionan algunos atisbos interesantes, aunque elementales, de costumbres y conductas sexuales en otros países y culturas. Estos trabajos permiten mostrar la diversidad de la expresión humana y mejorar la comprensión de las normas y valores que pueden ser universales, para ello se compararan los resultados con los de otros estudios interculturales como los de Ford y Beach (1951) realizados en 190 sociedades o los trabajos de Buss $(1985,1989,1994)$.

Así mismo la OMS, motivada por la necesidad imperiosa de comprender mejor las diversas maneras en las que se propaga el virus del SIDA, comenzó a finales de los ochenta, a realizar amplias investigaciones sobre la conducta sexual en numerosos países, cuyos resultados compararemos con los obtenidos en este estudio (Booth, 1989).

Los datos de nuestra encuesta, representativos de una franja de edad (20 a 27 años) son de interés para educadores, profesionales de la salud y el público en general, ya que muestran cuándo se inicia el interés por el sexo, las relaciones sexuales y las decisiones que toman respecto a la protección de su salud.

\section{Método}

\section{Participantes}

La población investigada son los estudiantes de Humanidades de la Universitat Pompeu Fabra (UPF) que tienen una media de edad de 22 años -el mínimo de 19 y el máximo de 41; el 96,2\% 
de la muestra está comprendida entre los 20 a 27 años. La encuesta se inició en el curso 19992000 y finalizó el 2003-2004 participando un total de 838 alumnos (253 varones y 585 mujeres). Todos los participantes eran voluntarios y anónimos y correspondían a los alumnos de tercer y cuarto curso de la licenciatura de Humanidades. El universo fue el conjunto de estudiantes de Humanidades que se matriculaban a las asignaturas impartidas por los autores era de 240 estudiantes/año, así la totalidad de alumnos de los cursos (tercero y cuarto) durante el periodo de estudio fue de 1200. La encuesta se realizaba en un día de clase y en cada formulario el estudiante sólo indicaba la edad, el sexo y la fecha de la realización, además de responder a las preguntas. $\mathrm{Al}$ recoger los formularios se les identificaba con un número para el control de la muestra, la codificación y para garantizar el anonimato.

\section{Instrumentos}

La encuesta, elaborada por los autores, consistía en 42 preguntas acerca de sus experiencias y actitudes sexuales. En concreto en este artículo se analizan las relacionadas con la edad de la primera relación sexual completa, las primeras experiencias, (homosexuales, heterosexuales, onanistas), las preferencias (masturbación, caricias, sexo oral..), las medidas de prevención de ETS (Enfermedades de Transmisión Sexual), la contracepción, la importancia de la actividad sexual, la expectativa en la procreación, la vinculación entre la relación sexual y las relaciones amorosas y en general la importancia que otorgan a las relaciones sexuales en su equilibrio personal.

\section{Procedimiento}

El error de la muestra, en el supuesto de una selección aleatoria, para un nivel de confianza 95\% $(2 \sigma)$ es de $0,01(1 \%)$ para el conjunto de la muestra, siendo $\mathrm{N}=1200$ que era la totalidad de alumnos en los cursos de tercero-cuarto durante el período de estudio.

En el análisis estadístico confirmatorio se igualan las muestras de ambos sexos N=500 (250 varones y 250 mujeres) para analizar si existen diferencias en las respuestas en función del sexo. La muestra de las mujeres $(n=585)$, y de los hombres $(n=253)$, se seleccionaron al azar con una opción que tiene el programa de análisis estadístico SPSS.

\section{Análisis de los datos}

Las pruebas estadísticas empleadas para las variables cualitativas son la tablas de contingencia con el cálculo de la $\chi^{2}$ de Pearson y los residuos ajustados (empleando como referencia el valor estadístico de prueba 1,96 en valor absoluto para una distribución normal y un nivel de significación de 0,05 (Haberman, 1978). En los casos que los valores esperados de al menos el $80 \%$ de las celdas de la tabla de contingencia eran inferiores a 5 se utilizó la prueba exacta de Fisher. La prueba t de Student se utilizó para determinar las diferencias sexuales en las variables numéricas de la encuesta.

\section{Resultados}

Al plantear una pregunta genérica sobre la edad de las primeras relaciones sexuales y la edad que tenía la pareja se obtienen diferencias con las respuestas facilitadas cuando se les cuestiona directamente. Más de la mitad de los universitarios $(54,9 \% \quad n=460)$ su primera relación sexual se produce entre los 17 a 20 años, el 18,6 \% $(n=156)$ antes de los 17 años, y el 15,8\% ( $n=132)$ ya tenía más de 20 años, tal y como se muestra en la figura 1 . No se observan diferencias estadísticamente significativas entre varones y mujeres respecto a la edad de inicio de las relaciones sexuales en pareja $(\chi 2(3)=0,125 \mathrm{p}>0,05)$. 
Fig 1. Edad de las primeras relaciones sexuales

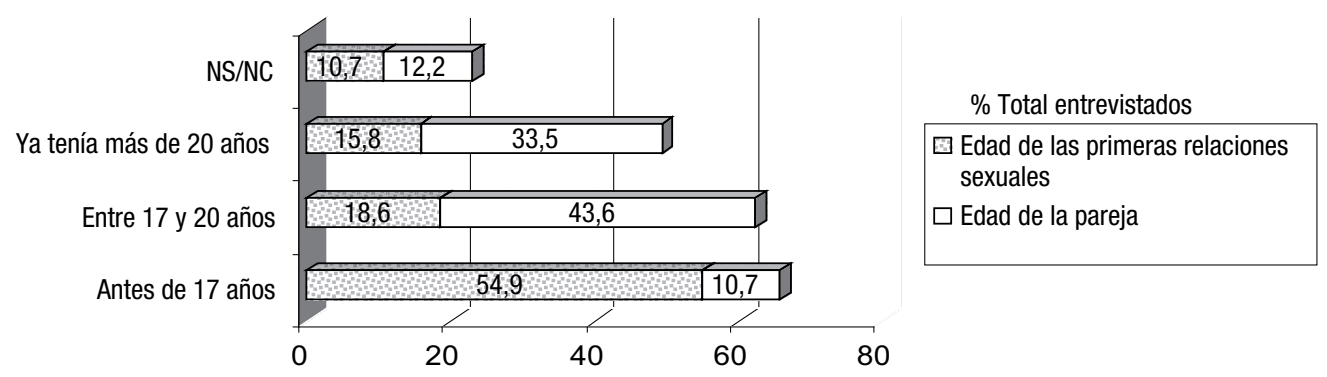

Respecto a la edad que tenía la pareja en la primera relación sexual también la mayoría (43,6\% $(\mathrm{n}=365))$ tenían entre 17 y 20 años, el 33,5\%(n=281) ya tenía más de 20 años y sólo un 10,7 $\%(\mathrm{n}=90)$ antes de los 17 . Se obtienen diferencias estadísticamente significativas entre hombres y mujeres (Fig 2), siendo éstas las que la pareja era mayor de 20 años y en cambio en los hombres tenia menos de $17\left(\chi^{2}(3)=24,79 \mathrm{p}<0,001\right)$.

Fig 2. Edad de las primeras relaciones sexuales en función del sexo

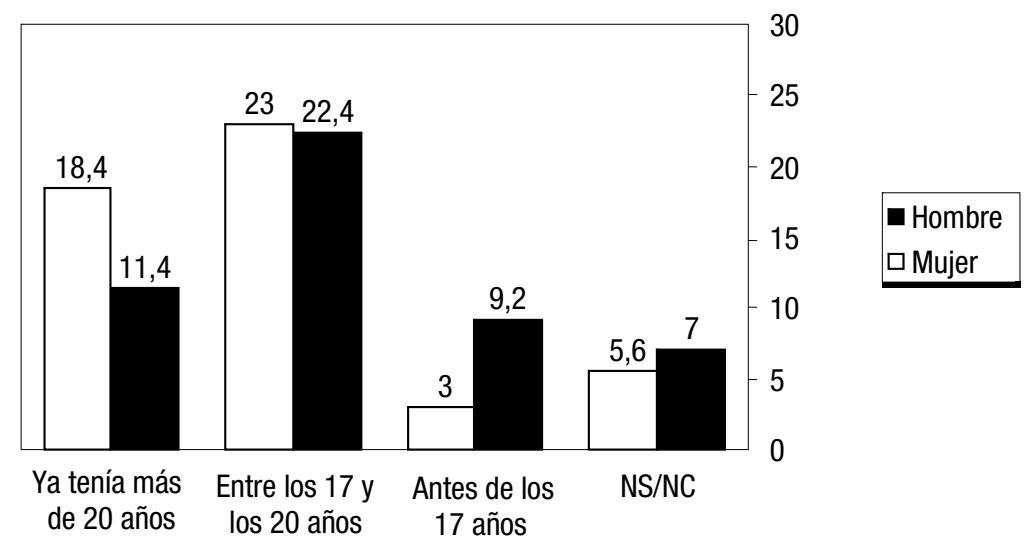

En cambio cuando se les pregunta directamente la misma cuestión y sólo matizando que hicieran referencia a la primera relación sexual completa se obtiene que la media de edad en la que mantienen una relación sexual completa está en 15,4 años (Desv 7,1) el máximo es a los 30 años. No se observan diferencias estadísticamente significativas entre hombres y mujeres respecto a la edad media en que establecen la primera relación sexual completa $(\mathrm{t}(0,005,498)=1,183 ; \mathrm{p}>0,05)$

La edad media del despertar del interés sexual es 13, 5 años (Desv tipica 3,8) y la máxima a los 22. Se obtienen diferencias estadísticamente significativas entre sexos en la edad de percepción del interés sexual $\left(\mathrm{t}_{(0,05,498)}=-3,11 ; \mathrm{p}<0,05^{*}\right)$. La edad media en los hombres es de 12,7 años y de 13,7 en las mujeres.

Las primeras experiencias sexuales mayoritariamente son heterosexuales (ver Fig 3). Las mujeres responden más a la tipologia heterosexual y los hombres más a las onanistas $(\chi 2=(3)=57,84$; $\mathrm{p}<0,001 * *)$ ( Fig 4) . 
Fig 3. Primeras experiencias sexuales

\section{$\%$ Total entrevistados}

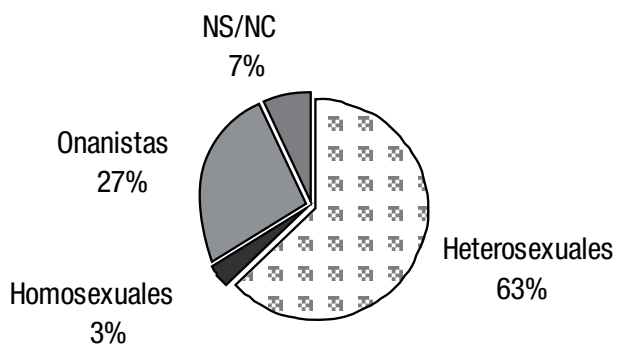

Fig 4. Diferencias entre hombres y mujeres en la tipologia de las primeras relaciones sexuales

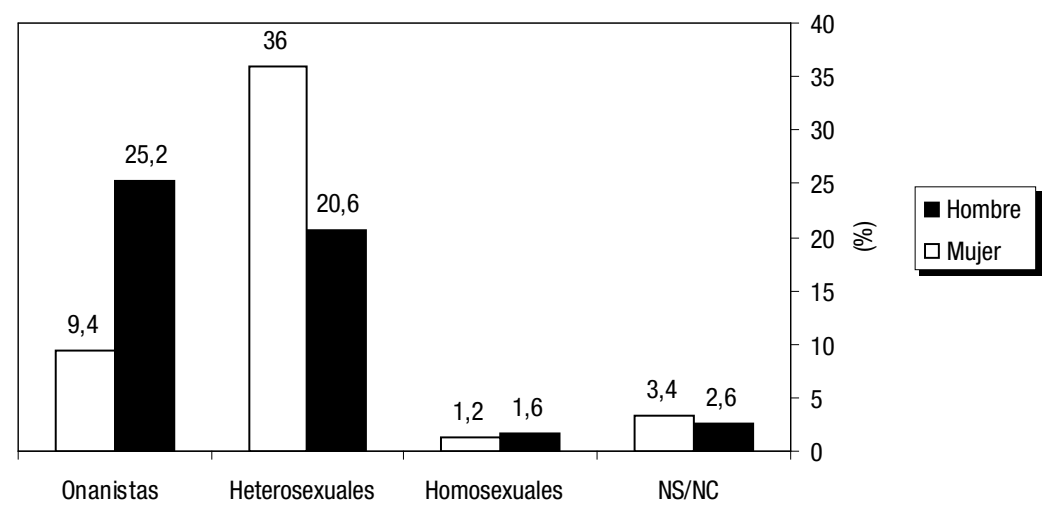

El 55,1\% ( $\mathrm{n}=462)$ manifiesta mantener relaciones sexuales de forma regular (mínimo una vez a la semana). Se obtienen diferencias estadísticamente significativas entre hombres y mujeres, siendo éstas las que afirman mantener relaciones sexuales de forma regular ( $\mathrm{F}=9,21, \mathrm{p}=0,004)$ (Figura $5 \mathrm{a}, \mathrm{b}$.)

Fig 5a. ¿Mantienes relaciones sexuals de forma regular?

\% Total Entrevistados

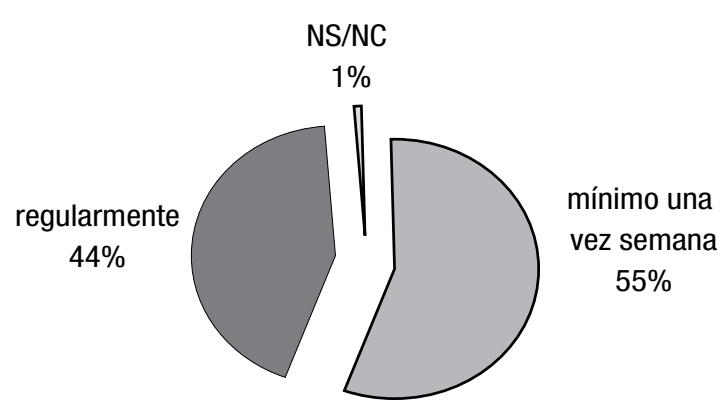


Fig5.b ¿Mantienes relaciones sexuales de forma regular? Diferencias entre sexos.

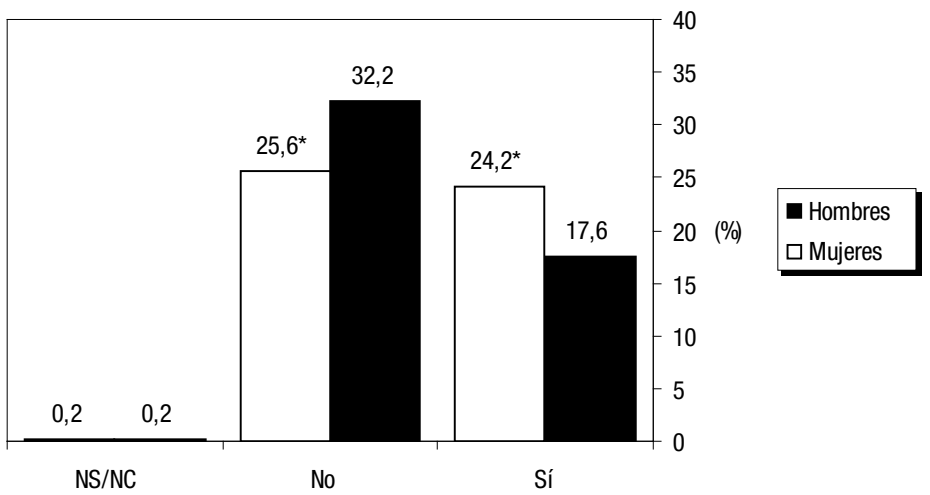

Más de la mitad de los universitarios encuestados atribuye su capacidad de contención sexual a la fidelidad tal y como se muestra en la figura 6 .

Fig 6. Capacidad de contención o represión sexual

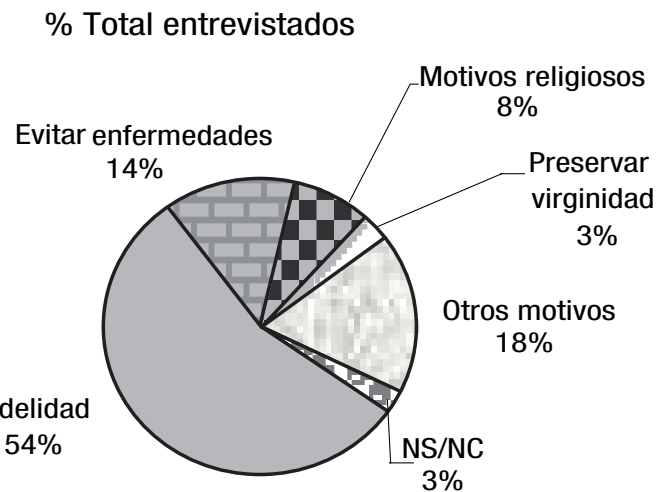

Se obtienen diferencias estadísticamente significativas entre varones y mujeres en sus respuestas $\left(\chi 2(5)=14,113 \mathrm{p}<0,05^{*}\right)$, las mujeres responden más que la contención es por fidelidad y virginidad en cambio, los hombres para evitar enfermedades.

La mitad de los universitarios no tiene una preferencia horaria para mantener relaciones sexuales (Fig 7). Se observan diferencias estadísticamente significativas en las respuestas de hombres y mujeres. Los hombres responden más a cualquier hora $(\chi 2(6)=16,74 p<0,05)$.

Fig.7 Preferencia horaria para mantener relaciones sexuales $\%$ Total entrevistados

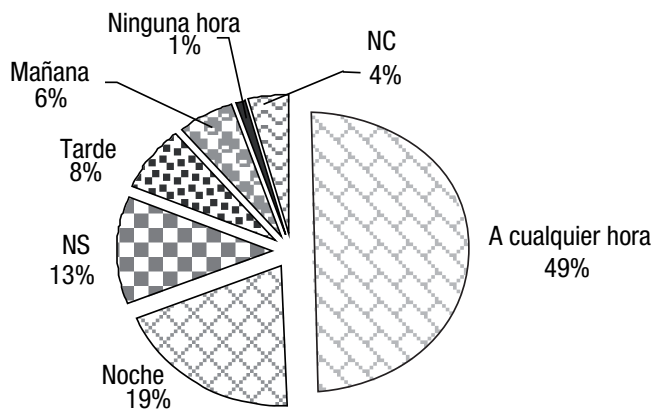


El 40,8\% de los entrevistados afirma alcanzar el orgasmo habitualmente (Fig 8). Mayoritariamente los hombres responden más que las mujeres que alcanzan el orgasmo siempre $(\chi 2 \quad(5)=85,51$; $\mathrm{p}<0,001)$.

Fig 8. ¿Alcanzas el orgasmo?

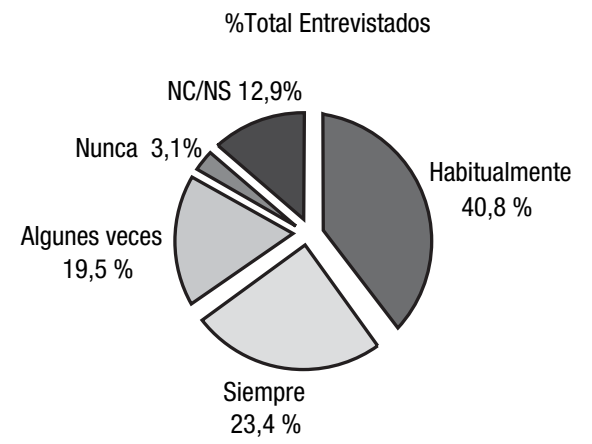

Más de la mitad de los entrevistados (55\%) vincula las relaciones sexuales con las amorosas, el $43 \%$ no y el $2 \%$ no contesta. Cuando se comparan las respuestas de hombres y mujeres, se observan diferencias estadísticamente significativas en las respuestas, así son las mujeres las que más vinculan las relaciones sexuales a las amorosas $\left(\chi^{2} \quad(2)=31,09 ; p<0,001 * *\right)$.(Fig 9).

Fig 9. Diferencias en las respuestas de los entrevistados en función del sexo

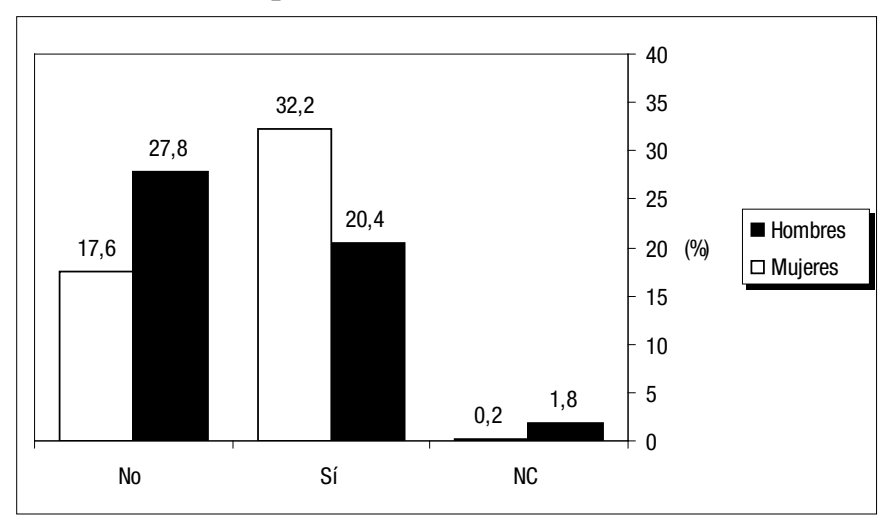

El 59,4 \% $(n=498)$ de los entrevistados marca como importante para su equilibrio personal el mantener relaciones sexuales (Fig. 10). No se obtienen diferencias estadísticamente significativas al comparar las respuestas de los varones y de las mujeres.

Fig 10. Importancia de las relaciones sexuales en el equilibrio personal

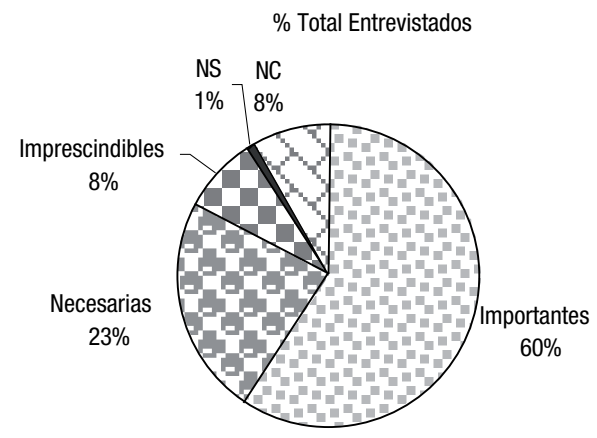


Resultados similares se obtiene cuando se les pregunta por el grado de importancia que dan a la actividad sexual en su vida cuotidiana, la mitad otorga una importancia media a la actividad sexual (Fig 11)

Fig 11. Importancia de la actividad sexual en la vida cuotidiana

$\%$ Total entrevistados

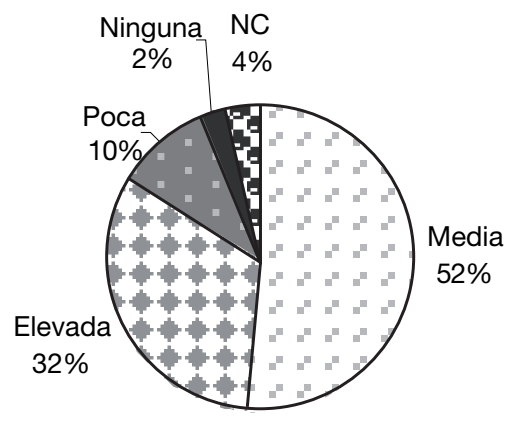

Aunque no se obtienen diferencias estadísticamente significativas entre hombres y mujeres al comparar las respuestas en función del sexo, $\left(\chi^{2}(4)=9,42 ; \mathrm{p}=0,051\right)$, los hombres le dan una importancia elevada a la actividad sexual.

Las preferencias por diferentes actividades sexuales marcadas por orden de prioridad se muestran en la fig 12.

Fig 12. Preferencias por diferentes actividades sexuales

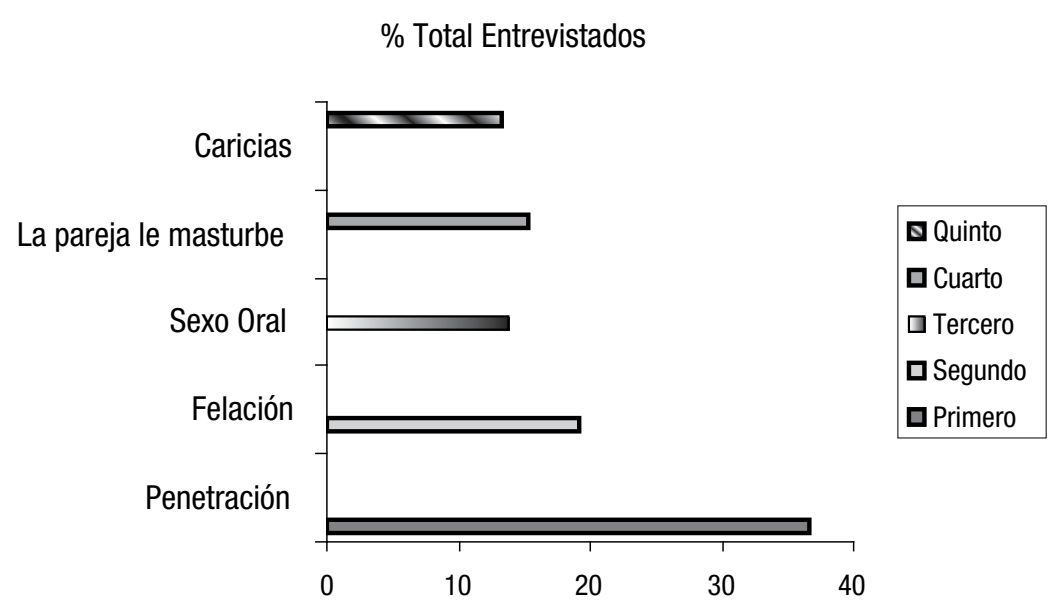

No se observan diferencias estadísticamente significativas entre hombres y mujeres en las respuestas sobre la masturbación ni en la penetración. En cambio las mujeres prefieren que su pareja las masturbe $\left(\chi^{2}(4)=44,42 ; \mathrm{p}<0,001^{* *}\right)$ y las acaricie $\left(\chi^{2}(5)=77,75 ; \mathrm{p}<0,001^{* *}\right)$. Los hombres prefieren la felación $\left(\chi^{2}(5)=142,5 ; \mathrm{p}<0,001 * *\right)$.

Las dos terceras partes de los entrevistados utilizaron métodos anticonceptivos la última que vez que tuvieron una relación sexual (Fig 13). No se observan diferencias estadísticamente significativas en las respuestas en función del sexo $\left(\chi^{2}(2)=1,904 \mathrm{p}>0,05\right)$ 
Fig 13.¿Utilizaste métodos anticonceptivos en la última relación sexual?

\section{\%Total Entrevistados}

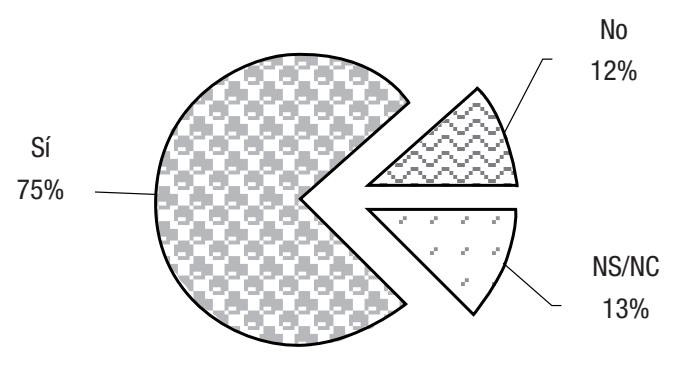

La mayoría de los entrevistados afirma disponer información sobre anticonceptivos, SIDA, dietas, enfermedades infecciosas, ETS (Enfermedades de Transmisión Sexual) (Fig 14)

Se obtienen diferencias estadísticamente significativas en función del sexo en la información que tienen sobre el SIDA, siendo los hombres quienes responde con frecuencias superiores ( $\mathrm{F}=9,74$ $\mathrm{p}<0,005)$. Las mujeres en cambio, tienen más información sobre dietas $(\mathrm{F}=14,16 \mathrm{p}<0,05)$.

Fig 14. Información que disponen los entrevistados

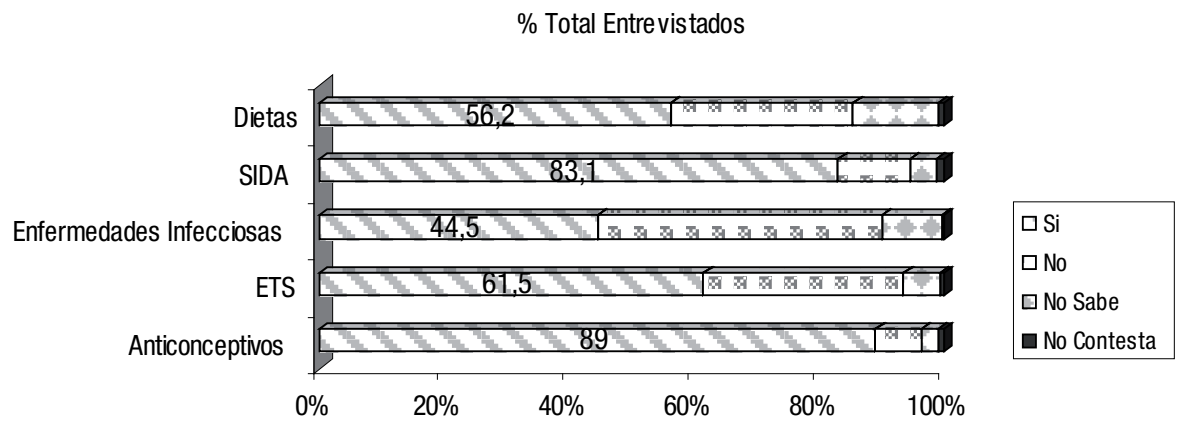

El preservativo es el método más utilizado para evitar el embarazo (Fig 15). Se obtienen diferencias estadísticamente significativas en las medidas empleadas por ambos sexos para evitar el embarazo. Las mujeres prefieren las pastillas anticonceptivas $\left(\mathrm{F}=24,05 \mathrm{p}<0,05^{*}\right)$ y el preservativo $\left(\mathrm{F}=38,1 ; \mathrm{p}<0,001^{* *}\right)$. Los hombres prefieren que sus parejas utilicen el DIU $\left(\mathrm{F}=12,13 ; \mathrm{p}<0,05^{*}\right) \mathrm{o}$ bien optan por el coito interruptus $\left(\mathrm{F}=12,11 ; \mathrm{p}<0,05^{*}\right)$

Fig 15. Medidas empleadas para evitar el embarazo $\%$ Total entrevistados

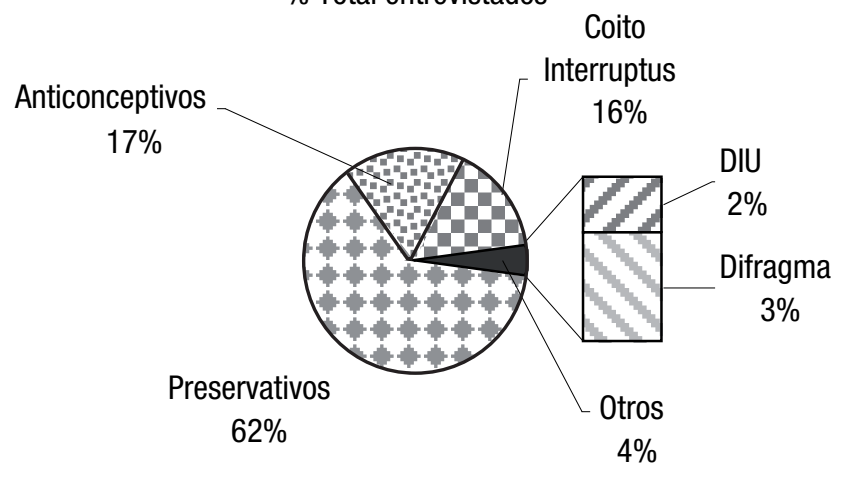


También vuelven a optar mayoritariamente por el preservativo $(78,2 \%)$ como medida para evitar las enfermedades de transmisión sexual (Fig 16). No se observan diferencias entre hombres y mujeres en sus respuestas $(F=3,69 ; p>0,05)$

Fig 16. Medidas preventivas para evitar ETS

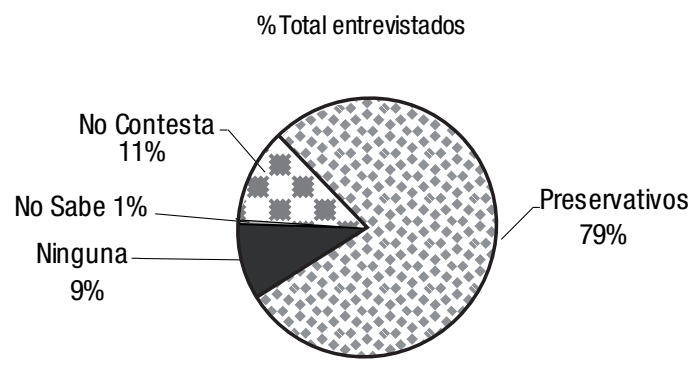

Discusión

\section{Edad del despertar del interés sexual y de las primeras relaciones}

Los resultados obtenidos pueden compararse con los publicados por Demoscopia en 1997 que realizó una encuesta similar entre los universitarios, pero de ámbito nacional, de todas las áreas de conocimiento, distintos cursos y carreras $(\mathrm{n}=4000)$. Al comparar los datos de inicio de las relaciones sexuales en la encuesta de demoscopia el 65\% marcaba el intervalo entre 17 a 20 años, en la muestra realizada en Humanidades de la UPF los valores son ligeramente inferiores 54,9\%. Las diferencias aparecen entre varones y mujeres en las edades que tenían sus parejas en la primera relación sexual, así las parejas de las mujeres son de edades mayores de 20 años y los hombres menores de 17 (más jóvenes).

Aunque no sea un dato que se pueda comparar con la encuesta anteriormente citada, si tiene interés resaltar una curiosidad, la edad media que se despierta el interés sexual es a los 13 años pero cuando se analizan los datos diferenciando hombres de mujeres aparecen las diferencias, así el despertar es un año antes en los chicos $(12,7)$ que en las chicas $(13,7)$ es curioso que se obtengan estos datos cuando la pubertad (periodo de rápidos cambios físicos) se da más o menos dos años antes en las niñas que en los niños. Estas diferencias se desdibujan cuando se analiza la edad media en la que mantienen las relaciones sexuales completas, 15,4 años, edad que es independiente del sexo. La media en España según la encuesta realizada por Durex Survey en 2004 (www.durex.com) está en 17,7 años y por delante están Islandia $(15,7)$, Alemania $(16,2)$ y otros países europeos.

Los resultados de estudios similares realizados en EEUU revelan una fuerte tendencia ascendente en el coito adolescente en las últimas décadas y que esta tendencia se ha nivelado más o menos en los últimos 10 años. Las tasas de coito informadas por Kinsey, Pomeroy y Martin, (1948) y Kinsey (1953) corresponden a $20 \%$ en mujeres y $45 \%$ en hombres. Según la encuesta de la NHSLS se observa que en las últimas décadas se ha presentado una tendencia a la experimentación del primer coito a una edad más temprana en ambos sexos (15,6 años para los chicos y 16,2 años para las chicas), que es constante a lo largo de un amplio espectro de grupos étnicos. La encuesta muestra que existen diferencias geográficas y que EEUU y Canadá muestran los promedios de edad más jóvenes en las primeras relaciones sexuales. La mayor incidencia del coito adolescente entre ambos sexos, particularmente pronunciada en los años setenta y ochenta, refleja los cambios en las actitudes hacia las relaciones sexuales no maritales de los adolescentes, (Crooks \& Baur, 2000; Durex Survey, 2004). 
Hoff, Greene y Davis, (2003) en la encuesta nacional en Estados Unidos, sobre adolescentes con una muestra de $n=1800$ jóvenes de tres clases de edad (13-14 años); (15-17) y de (18-24) obtiene que el $9 \%$ de los adolescentes activos sexualmente dicen que sus primeras relaciones fueron a los 13 años. La encuesta realizada a estudiantes de secundaria de Australia por Smith, Agius, Dyson, Mitchell, y Pitts, (2003) ( $\mathrm{N}=2388)$ entre 10-12 años, muestra que la mayoría son activos sexualmente. El 45,5\% responden que dan o reciben sexo oral y mantienen o han mantenido relaciones completas, el $25 \%$ de los jóvenes de 10 años y la mitad de los de 12 . Además cerca de una cuarta parte $(25,9 \%)$ de los estudiantes sexualmente activos, dicen haber tenido sexo no deseado, bajo los efectos de la bebida y las drogas.

Los factores que pueden motivar a los adolescentes a tener relaciones sexuales tienen una base hormonal. La testosterona aumenta el deseo y la excitabilidad sexual en ambos sexos. A algunos adolescentes los mueve la curiosidad y un sentido de querer experimentar. Cerca de la mitad de los varones y una cuarta parte de las chicas del estudio de Laumann, Gagnon, Michale, y Michaels (1994) informan que su razón fundamental para mantener una relación sexual es la curiosidad y la sensación de que estaban preparados para el sexo. Muchos adolescentes consideran las relaciones sexuales como una expresión natural de afecto o amor (Sprecher \& McKinney, 1993). Además del afecto otra razón para tener una relación sexual es la presión de los compañeros, la presión por parte de la persona con la que salían o un sentido de obligación por lealtad a la pareja, son otras razones que pueden influir en que los adolescentes mantengan relaciones sexuales (Lauman, et al.1994).

Una variedad de estudios realizados en EEUU muestran de manera constante que los afroamericanos tienen más probabilidades de mantener relaciones sexuales en la adolescencia que los blancos o los hispanos (Centres for Disase Control, 1996; Kissinger et al. 1997; Michael, Gagnon, Laumann, y Kolata, 1995; Laumann et al.1994). Estos estudios revelan también que los jóvenes afroamericanos suelen tener su primera experiencia sexual a una edad más temprana que los hispanos o los blancos, el 24,2\% manifiesta haber tenido relaciones antes de los 13 años, en comparación con el 8,8\% de hispanos y el 5,7\% de blancos.

El estudio de la NHSLS también da cuenta de una marcada diversidad étnica en las experiencias sexuales de los adolescentes. La encuesta realizada a nivel nacional revela que alrededor de la mitad de los encuestados varones afroamericanos manifiesta haber tenido relaciones sexuales con 15 años, la mitad de los varones hispanos a los 16, 5 años y la mitad de los blancos cuando tenían 17 años. Las cifras para las mujeres revelan que la mitad de las afro americanas tuvo relaciones sexuales casi a los 17 años, la mitad de las blancas a los 17,5 años y la mitad de las hispanas cerca de los 18 años (Michael et al. 1995). Las explicaciones sobre estos datos plantean que las diferencias étnicas en las experiencias sexuales de los adolescentes pueden relacionarse más con la condición económica que con la raza o el origen étnico. Sugieren que la pobreza es un buen indicador de la actividad sexual entre los adolescentes (Brewster, 1994; Day, 1992; Kissinger et al. 1997).

Otras encuestas realizadas en Gran Bretaña (Hall, 2006) muestran que los adolescentes son más cautos, así el $64 \%$ de entre 16 a 24 años manifiestan que esperaron hasta los 16 años para mantener relaciones sexuales y sólo un $23 \%$ tuvo relaciones sexuales a los 16 y un $46 \%$ esperaron a ser más mayores. Esta encuesta online dirigida por el Departamento de Salud fue contestada por 20.000 jóvenes de los que el $60 \%$ tenía entre 22 y 24 años.

\section{Cómo son las primeras relaciones sexuales}

Mayoritariamente las primeras experiencias sexuales son heterosexuales (63\%) pero los hombres responden más a las onanistas. Diferencias similares aparecen en el estudio sobre frecuencia de la masturbación de Laumann et al. (1994) en le que, para el mismo intervalo de edad, los varones se masturban un 30\% y las mujeres el 9,4\%. Más de la mitad de los universitarios (55\%) mantienen relaciones como mínimo una vez a la semana y las mujeres afirman que mantienen relaciones de forma regular, más que los hombres. 
La encuesta realizada a estudiantes de secundaria en Australia por Smith, et al. (2003) muestra que la mayoría son activos sexualmente y que el $2 \%$ de las relaciones recientes eran heterosexuales. El 3,3\% de lo chicos y el 6,7 \% de las chicas, informan sentirse atraídos por su propio sexo. Contestan que se sienten inseguros el $1,3 \%$ de los chicos y el $2,1 \%$ de las chicas.

Los motivos que aducen para reprimirse sexualmente son diferentes en hombres que en mujeres, así éstas responden más que lo hacen por fidelidad y para mantener la virginidad. Los varones dicen que es para evitar enfermedades.

La mitad de los universitarios no muestran una preferencia horaria para mantener relaciones sexuales y son los hombres, los que más responden que a cualquier hora. Según una encuesta publicada en una revista de divulgación Quo (encuesta realizada por la empresa de sondeos Iope Test $n=647$ entrevistas telefónicas realizadas a mayores de 18 años, error de $\pm 3,9 \%$ ) mostraba que el $54 \%$ de los varones españoles prefieren mantener relaciones sexuales por la noche frente al $42 \%$ de las mujeres, sólo el 14\% manifestaba a cualquier hora. El deseo sexual es un fenómeno biológico marcado por la cantidad de hormonas, que son las responsables del comportamiento sexual, que varían en función de la hora del día, de la persona, del sexo, del clima. Además nuestro metabolismo fluctúa de acuerdo a cambios rítmicos, los más estudiados son los circadianos que se corresponden con los cambios solares y que varían cada $24 \mathrm{~h}$, por ejemplo el nivel hormonal que influye en el deseo -aumento de testosterona en el hombre y de estrógenos en la mujer-alcanza su grado máximo entre las 7 y las 12 de la mañana y el más bajo a partir de las $18 \mathrm{~h}$. Además de los ciclos circadianos, en las mujeres, los cambios hormonales durante la ovulación (estrógenos y progesterona) son los responsables de los cambios de sensaciones físicas y psicológicas, incluido el deseo sexual. Así pues la variabilidad en las preferencias horarias es amplia y multifactorial.

El 55\% de los entrevistados vinculan las relaciones sexuales con las amorosas y son las mujeres las que responden más afirmativamente a esta pregunta. Resultados similares son los que presenta el estudio del amor romántico en otras culturas, Jankowiak y Fisher, (1992) documentaron la existencia de esta modalidad de amor en 147 de las 166 sociedades estudiadas. También propusieron que la ausencia en las otras 19 sociedades se debía quizá a una deficiencia en sus métodos de estudio más que a un reflejo de una verdadera sociedad carente de amor. Los hallazgos de Jankowiak y Fisher, (1992) contrastan en gran medida con la noción de que el amor romántico constituye un rasgo universal humano. El estudio con otro enfoque realizado por Meston y Buss (2007) muestra cómo entre las diez primeras razones por las que tienen relaciones sexuales aparecen, tanto en hombres como en mujeres, el querer mostrar afecto y expresar amor. La encuesta se realizó con una muestra de 444 hombres y mujeres de entre 17 y 52 años que tenían que confeccionar una lista de motivaciones sobre el porqué practicaba el sexo. Ambos esgrimen como una de las principales razones para acabar teniendo sexo el hecho de que se hubiera dado una situación romántica. Este estudio tiene la segunda fase realizada con 1500 estudiantes de psicología que debían clasificar por orden de importancia las 237 razones de la muestra anterior, en función de sus experiencias. En este estudio Meston y Buss (2007) muestran que los hombres son más propensos a ser oportunistas ante la posibilidad de tener relaciones sexuales, de manera que ante la ocasión y la persona dispuesta se lanzarían con más facilidad. Por su parte, ellas tienen más tendencia a sentir necesidad de complacer.

Leigh (1989), enumera siete u ocho razones para tener una relación sexual como buscar placer, expresar cercanía emocional, reproducirse, contentar a la pareja, hacer una conquista o liberar tensión sexual. Los estudios que permiten hablar de las emociones y las sensaciones evidencian que las diferencias entre sexos son mínimas.

Ambos sexos consideran que las relaciones sexuales son importantes para su equilibrio personal. Es más, cuando se les volvía a preguntar sobre la importancia de la actividad sexual en la vida cuotidiana marcaban la opción "media" la mitad de los encuestados y sólo una tercera parte consideraba que tenía una importancia "elevada". Cuando se comparan estos resultados con datos de población de edad similar en la encuesta realizada en Australia en 2006 (20-24 años) n=735 a la pregunta qué es lo que más les preocupa/interesa, las respuestas son: el 28,1\% la imagen corporal y la sexualidad el 13,9\%; por sexos la respuesta es de los chicos el 15,9\% y las chicas el 11,8\%. 
Probablemente las diferencias en los porcentajes sobre la importancia de las relaciones sexuales está más condicionada en cómo se formula la pregunta que en que existan diferencias entre estas dos poblaciones.

La satisfacción de la experiencia sexual se puede medir a través del orgasmo, o de informes subjetivos. Normalmente la satisfacción sexual se asocia a una aplicación correcta de las técnicas sexuales. El orgasmo es una respuesta compleja, física y mental, contextualizada socialmente y específica de cada individuo. Esto es válido tanto para hombres como para mujeres. Pero no siempre se alcanza el orgasmo en las interacciones sexuales; en concreto en las mujeres se estudia la influencia de factores psicosociales incluyendo la edad, la educación, el estatus social, la religión, la personalidad y la tipologia de las relaciones (Meston, Levin, Sipski, Hull, \& Herman, 2004). Los universitarios encuestados mayoritariamente contestan que alcanzan el orgasmo (64\%) si se suman las respuestas de siempre y habitualmente, significativamente los hombres responden más "siempre" que las mujeres. Según diversas encuestas, entre el 31 y el 50 por ciento de las mujeres de Inglaterra, EEUU y Alemania experimentan el orgasmo casi siempre y sólo del 2 al $14 \%$ de las encuestadas no lo experimentan nunca (Kinsey et al. 1953; Chesser, 1957; Fisher, 1973; Eysenck 1976; Hite 1976). Además según los resultados de estas encuestas quienes experimentan el orgasmo son sobre todo aquellas mujeres que mantienen una buena relación de pareja. En el estudio de Laumann et al. (1994) tres cuartas partes de los hombres informaban que siempre alcanzaban el orgasmo, en cambio las mujeres sólo el $29 \%$.

Respecto a las preferencias en las relaciones sexuales por orden de prioridad no hay diferencias entre hombres y mujeres en la masturbación ni en la penetración, en cambio las mujeres prefieren que su pareja las masturbe y las acaricie y los hombres prefieren la felación. La encuesta realizada entre estudiantes universitarios por Elliot \& Brantley, (1997) con una muestra de $n=2000$, sobre la frecuencia con la que se masturban, el $50 \%$ de los hombres respondían que dos o tres veces por semana, frente al $16 \%$ de las mujeres.

\section{ETS y anticoncepción}

En nuestro estudio sobre una población de estudiantes universitarios obtuvimos que dos terceras partes de los entrevistados utilizaron algún método anticonceptivo la última vez que tuvieron una relación sexual, es un dato inferior al obtenido y publicado por Demoscopia (1997) que apuntaba al $90 \%$ el uso de métodos anticonceptivos y profilácticos. El preservativo es el método más utilizado para evitar el embarazo. Las mujeres prefieren las pastillas anticonceptivas y los hombres que sus parejas utilicen el DIU o bien optan por el coito interruptus. El preservativo vuelve a ser el elegido como medida para evitar las ETS en ambos sexos. Respecto a la información que disponen sobre anticonceptivos, ETS, SIDA, o Dietas alimentarias, observamos diferencias con lo obtenido por Demoscopia en la información que dicen disponer sobre ETS en 1997 el 83\% de los universitarios contestaban que tenían información sobre ETS en 1999-2004 sólo el 60\%, así mismo sobre enfermedades infecciosas en 1997 el $70 \%$ frente a el 44,5\% y por último las dietas del $71 \%$ que en 1997 afirman tener información sobre las dietas adecuadas ahora se obtiene un 56\%. No existen diferencias en la información que disponen sobre el SIDA en 1997 el 89\% y en este estudio el $83,1 \%$.

Comparando nuestros resultados con los obtenidos en otras encuestas similares, en otros países como la de Cole (2001) realizada a jóvenes Británicos de edades comprendidas entre los 17 a los 25 años, señalan que la información que tienen los jóvenes sobre métodos anticonceptivos proviene de la televisión y las revistas, las chicas suelen obtener la información de las revistas y de sus madres. La mitad de las chicas manifiestan que les hubiera gustado recibir esta información de sus profesores. Otras encuestas realizadas por Pettifor et al. (2005) en Sudáfrica, con una muestra nacional $n=$ 11.904 y edades comprendidas entre los 15 y 24 años muestra la eficacia de los programas dirigidos a los jóvenes para el uso de preservativos para evitar ETS, SIDA y embarazos no deseados. Así estos programas educativos reducen la prevalencia de estas enfermedades pero son difíciles de implantar por factores contextuales que dificultan el cambio conductual. 
Otros estudios como el de Smith et al. (2003) en Australia con una muestra de N=2388 entre jóvenes de 10 a 12 años muestra que el uso de preservativos es común para evitar embarazos en los jóvenes de 10 años, así el 65,8\% informan que siempre los usan. Este porcentaje es inferior en los de 12 años $(51,8 \%)$ compensado por el elevado uso de pastillas anovulatorias. Así el $74 \%$ de los jóvenes de 10 años y el 56,6\% de los de 12 informan que utilizan el preservativo más como sistema para evitar el embarazo que para evitar las ETS. De la proporción que usan preservativos, $60 \%$ de los chicos siempre y el $31 \%$ dice que a veces. El $46 \%$ de las chicas los usan siempre frente al $44 \%$ que a veces. En la última relación sexual El 73\% tenían un preservativo disponible y lo usaron el 65\%. Los resultados de esta encuesta muestran que los jóvenes de 10 a 12 años son activos sexualmente y que son necesarios planes educativos para informar sobre SIDA y ETS.

En el mismo año Hoff et al. (2003) en la encuesta nacional sobre adolescentes con una muestra de $n=1800$ jóvenes de 13 a 24 años, señala que los jóvenes están más interesados en el sexo y en la salud sexual que en otros aspectos de salud de su vida. También que reciben una gran presión para tener relaciones sexuales. No obstante se detecta una falta de información sobre los riesgos para la salud de prácticas sexuales sin protección. Así informa que tres cuartas partes de los adolescentes activos sexualmente practican el sexo oral, una quinta parte de ellos desconoce las enfermedades de transmisión sexual vinculadas a esta práctica dos quintas partes lo considera sexo-seguro. También observa que bastantes jóvenes tienen percepciones equivocadas sobre los riesgos de salud asociados con las ETS y el SIDA y poseen información incompleta sobre: el sexo saludable, la efectividad de los preservativos frente a otros métodos contraceptivos, la prevención de ETS y la frecuencia y disponibilidad de los test de ETS y de SIDA. No obstante, 9 de cada 10 adolescentes consideran el preservativo como sexo seguro, el $71 \%$ otras formas de contracepción también las consideran seguras, aunque no ofrezcan protección contra las ETS. También 9 de cada 10 adolescentes activos sexualmente informan que han utilizado algún método contraceptivo en alguna ocasión, el $70 \%$ dice que utiliza un método contraceptivo o medidas de protección siempre.

La encuesta realizada online por el Departamento de Salud de Gran Bretaña (Hall, 2006) (n= 20.000 jóvenes entre 16 a 24 años) muestra el 38\% de los jóvenes entre 16 a 24 años nunca utiliza preservativo con una nueva pareja. Gran Bretaña es de los países europeos con los índices más altos en ETS. El 24\% no utiliza métodos contraceptivos la primera vez que mantienen relaciones sexuales. Esta encuesta mostró las deficiencias en la educación sexual, uno de cada diez manifiesta no haber recibido educación sobre sexualidad en la escuela y el 79\% que sólo había aprendido lo básico. El estudio de Gura y da Costa (1999), sobre fecundidad, comportamiento sexual y salud reproductiva de los jóvenes basado en una muestra $n=4528$ mujeres ( $28 \%$ casadas y el $68 \%$ solteras) y 1093 hombres de edades entre 14-25 años muestra que la tercera parte notificó haber usado algún tipo de método anticonceptivo en la primera relación sexual. El $75 \%$ de las mujeres que habían tenido relaciones sexuales el mes anterior, habían usado algún método anticonceptivo. El $90 \%$ de las mujeres que tenían pareja habían utilizado métodos anticonceptivos en alguna ocasión y el $63 \%$ lo usaba en la actualidad. El 58\% de ellas usaba un método moderno y el $86 \%$ de las mujeres tenían conocimientos relativos al SIDA, pero el 53\% no sentían que corrían riesgo de contraer esta enfermedad.

Un estudio reciente Cohen, Celestine-Michener, Holmes, Merseth, y Ralph, (2007) sobre una encuesta realizada a afroamericanos muestra a los jóvenes afroamericanos que usan métodos de protección para tener un sexo seguro más que los hispanos y blancos, el 77\% de los afroamericanos frente al $64 \%$ de los hispanos o el 66\% de los blancos. La encuesta se centra en 1590 jóvenes afroamericanos, blancos e hispanos de edades comprendidas entre los 15 a los 25 años y les pregunta sobre sus conductas y actitudes sexuales. Cerca del $90 \%$ de cada grupo manifiestan que pueden convencer a sus parejas para usar protección para tener relaciones seguras. Más del $90 \%$ de toda la muestra estaba de acuerdo en que la educación sexual fuera obligatoria en secundaria. 


\section{Conclusiones}

En la mayoría de países occidentales y otros desarrollados o en desarrollo, los jóvenes se inician en la vida sexual en edades cada vez más tempranas. En los universitarios la franja está en los 15,4 años como media, frente a los datos de los adolescentes de EEUU o Australia que empiezan a mantener relaciones sexuales dos o más años antes que los europeos.

Más de la mitad manifiesta mantener relaciones sexuales de forma regular. En la misma proporción vinculan las relaciones sexuales a las amorosas y más de dos terceras partes las considera importantes para su equilibrio personal.

Todo y tratarse de la población universitaria, por lo tanto con más educación y formación, no hay conciencia del riesgo de la transmisión de ETS. Se detecta la incongruencia que esta población a pesar de estar informada sobre los métodos anticonceptivos a la vez, se expone a relaciones sexuales sin protección.

\section{Referencias}

Booth, W. (1989). VHI seeks global data on sexual practices. Science, 244, 418-419.

Buss, D.M. (1985). Human mate selection. American Scientist, 73, 47-51.

Buss, D. M. (1989). Sex differences in human mate preferences: Evolutionary hypotheses tested in 37 cultures. Behavioural and Bran Sciences, 12, 1-49.

Buss, D.M. (1994). The evolution of desire. New York: EEUU. Basic books, Harper Collins Publishers.

Brewster, K. (1994). Race differences in sexual activity among adolescent women: The role of neighborhood characteristics. American Sociological Reviews, 56, 408-424.

Calvo, E. (1997). La hora feliz. Quo, 24-30.

Chesser, E. (1957). The sexual, marital and family relationship of the English woman. New York, Roy.

Cohen, C.; Celestine-Michener, J.; Holmes, C.; Merseth, J. L. \& Ralph, L. (2007). The attitudes and behaviours of young black Americans. Retrieved from http://blackyouthproject.com

Cole, E. (2001). Sex surrey highlights youngster's lack of knowledge. The Independent, 10-12.

Crooks, R. \& Baur, K. (2000). Nuestra sexualidad. México:México. International Thomson Editores, Séptima edición

Day, R. (1992). The transition to first intercourse among socially and culturally diverse youth. Journal of Marriage and the Family, 54, 749-762.

Elliot, L. \& Brantley, C. (1997). Sex on Campus. New York: Random House.

Eysenck, H. J. (1976). Sex and personality. London open books.

Fisher, S. (1973). The female orgasm: psychology, physiology, fantasy. New York: Basic Books.

Ford, C. \& Beach, F. (1951). Patterns of sexual behaviour. New York: EE UU. Harper \& Row.

Gura, N. \& da Costa, L. (1999): Adolescent fertility behavior: trenes and determinants in Northeastern Brazil. International Family Planning Perspectives, 25(3), 125-130.

Haberman, S. J. (1978). Analysis of qualitative data (Vol I). New York:EEUU. Academic Press.

Hall, S. (2006). Teenagers in no rush to have sex, biggest survey shows. The Guardian, 15 (08). Retreived from http://www.guardian.co.uk/uk/2006/aug/15/healthhandwellbeing.health 
Hite, S. (1976). The Hite report: A Nationwide study of female sexuality. New York: Dell.

Hoff, T.; Greene, L. \& Davis, J. (2003). National Survey of Adolescents and Young Adults: Sexual Health Knowledge, Attitudes and Experiences. Menlo Park, California:EEUU. Henry J. Kaiser Family Foundation

Jankowiak, W. \& Fisher, E. (1992). Cross-cultural perspective on romantic love. Ethnology, 31, 149-155.

Kinsey, A. C. (1953). Sexual behaviour in the human female. Filadelfia: Saunders.

Kinsey, A. C.; Pomeroy, W. B. \& Martin, C. E. (1948). Sexual behaviour in the human male. Philadelphia Saunders.

Kissinger, P.; Trim, S.; Williams, E.; Mielke, E.; Koporc, K. \& Brown, R. (1997). An evaluation of initiatives to improve family planning use by African-American adolescents. Journal of the National Medical Association, 89, 110-114.

Lauman, E. O.; Gagnon, J. H.; Michale, R. T. \& Michaels, S. (1994). The social organization of sexuality. Sexual practices in the United States. The complete findings from America's most comprehensive survey of sexual behaviour. Chicago: EEUU. The University of Chicago Press.

Leigh, B. (1989). Reasons for having and avoiding sex: gender, sexual orientation, and relationship to sexual behaviour. Journal of Sex Research, 26, 199-208.

Meston, C.; Levin, J. R.; Sipski, M. L.; Hull, E. M. \& Heiman, J. R. (2004). Women's Orgasm. En T. F. Lue, R. Basson, R. Rosen, F. Guiliano, S. Khoury \& F. Montorsi (Eds.), Sexual Medicine: Sexual dysfunctions in men and women (pp783-850). Paris, Francia.: Health Publications .

Meston, C., \& Buss, D. M. (2007). Why humans have sex. Arch Sex Behav, 36, 477-507.

Michael, R. T.; Gagnon, J. H.; Laumann, E. O. \& Kolata, G. (1995). Sex in America: A definitive survey. New York, NY: EE UU. Boston: Little, Brown.

National Health and Social Life Survey NHSLS (The sex survey), 1992, NORC Project \& National Health and Social Life Survey, NHSLS. Retrieved from http://cloud9.norc.uchicago.edu/faqs/ sex.htm

National survey of young Australians 2006, key and emerging issues. Mission Australia 160 pp. Retrieved from http//www.missionaustralia.com.au/downloads-survey

Smith, A.; Agius, P.; Dyson, S.; Mitchell, A. \& Pitts, M. (2003). National Survey of Secondary Students and Sexual Health. The Australian Research Centre in Sex, Health and Society, 2003.

Sprecher, S. \& McKinney, K. (1993). Sexuality. Newbury Park, CA: Sage.

Pettifor, A. E.; Rees, H. V.; Kleinschmidt, I.; Steffenson A. E.; Macphail, C.; Hlongwa-madikizela, L.; Vermaak, K. \& Padian, N. S. (2005). Young people's sexual health in South Africa: HIV prevalence and sexual behaviors from a nationally representative household survey. AIDS, vol. 19, (14):1525-1534.

Smith, A.; Agius, P.; Dyson, S.; Mitchell, A. \& Pitts, M. (2003). National Survey of Secondary students and sexual health (Australia, 2003). New South Wales Department of Education and Training. 


\section{Descripción de la revista y alcance de la línea editorial}

Summa Psicológica UST, Revista de Psicología de la Universidad Santo Tomás de Chile, es una publicación que acoge y difunde trabajos de carácter teórico y empírico enmarcados en, o conectados con, el campo de la ciencia psicológica. Entendemos aquí por 'campo psicológico' el extenso espacio de investigación y reflexión concerniente a la subjetividad y el comportamiento humano, cuya rica complejidad solicita, tal vez hoy más que nunca, la concurrencia e integración de múltiples marcos epistemológicos y formas discursivas distintas. Por ello, la revista quiere permanecer abierta tanto a trabajos de corte empírico-analítico (todas las líneas de investigación estándar dentro de la 'ciencia psicológica'), como a investigaciones y estudios de tipo teórico y conceptual (allí donde lo 'psicológico' se deja ver bajo la mirada de las humanidades y la reflexión filosófica). Todo lo que se exige, en términos tópicos, es que los escritos aborden temas insertos en el campo extenso de lo psicológico, o que tengan puntos relevantes de encuentro con él.

La periodicidad de la revista es semestral, y sus números aparecen en julio y diciembre de cada año.

La revista cuenta con una única sección: Artículos (sean de corte empírico o teórico conceptual).

Las opiniones expresadas en los artículos son de exclusiva responsabilidad de los autores y no comprometen a la Escuela de Psicología de la Universidad Santo Tomás, ni representan necesariamente el pensamiento de esta casa de estudios superiores.

\section{Normas de Publicación}

1. Los artículos enviados a Summa Psicológica UST deben ser inéditos, y no deben figurar simultáneamente en procesos de evaluación y selección para otras revistas.

2. Los autores recibirán vía e-mail el acuso de recibo de sus colaboraciones.

3. Sólo los artículos que cumplan con los requisitos de contenido y forma estipulados por Summa Psicológica UST (ver punto III. Instrucciones para los autores) serán enviados a evaluación.

3. Para su evaluación, los artículos son remitidos a pares académicos expertos (en el área temática del artículo, en aspectos metodológicos), asociados a Summa Psicológica UST en calidad de Consultores Externos. Todo ello bajo estricto anonimato del autor.

4. La decisión de aceptar o rechazar los artículos es tomada finalmente por el Comité Editor, teniendo como base las evaluaciones informadas por los expertos.

5. El proceso completo de evaluación y revisión de los artículos tiene un plazo máximo de 5 meses.

6. Tomada la decisión por parte del Comité Editor, ésta es comunicada vía e-mail al autor por el coordinador de la revista.

7. En caso de ser rechazado el artículo, el autor recibirá un resumen con las observaciones y sugerencias hechas por los evaluadores. El nombre de los evaluadores queda en estricta reserva y no es proporcionado al autor. El autor tendrá, a partir de la comunicación hecha por el coordinador, un plazo de 3 meses para hacer las correcciones pertinentes y volver a enviar el escrito. De no presentar el artículo dentro del plazo señalado, éste queda considerado como 'nuevo artículo' y pasa a ser evaluado desde el inicio del proceso.

8. El autor cuyo artículo es aceptado para ser publicado, tiene derecho a un ejemplar de la revista y a 10 separatas. Este material se envía por correo a la dirección señalada por el autor, dentro de los meses de julio-agosto y diciembre-enero, según se trate del primer o segundo número del año. En caso de haber más de un autor, el material se envía al autor principal. 
9. Para efectos de edición, el Comité Editor se reserva el derecho a efectuar las modificaciones y correcciones de prueba necesarias en los artículos para mantener el estilo formal de Summa Psicológica UST.

\section{Instrucciones para los autores}

1. Los artículos deben ser enviados vía E-mail y en formato Word al coordinador de la revista (dirección: summapsicologicaust@santotomas.cl). El archivo debe venir identificado con el apellido del autor, seguido de la abreviación del sistema de normas que ha utilizado para redactar el artículo (APA o MLA). Si hay más de un autor, debe identificarse solo con el apellido del autor principal (Ejemplo: SalinasAPA, MoralesMLA).

2. El artículo debe comenzar con el título en castellano e inglés, seguido inmediatamente de un resumen en castellano e inglés (de 100 a 150 palabras), y al menos tres palabras claves (en castellano y en inglés) que señalen los conceptos centrales tratados en el texto. El artículo no debe venir con el nombre del autor.

3. En archivo aparte debe venir el título del artículo, seguido del nombre del autor (o autores), su dirección postal, dirección E-mail, teléfonos, e institución a la que se encuentra afiliado actualmente (sea en calidad de académico o alumno).

4. Los artículos deben tener una extensión máxima de 10.000 palabras o 30 páginas escritas en hoja tamaño carta, párrafos justificados, a doble espacio y en letra Times New Roman $n^{\circ} 12$. Esta extensión incluye tablas, figuras, notas y referencias.

5. Los artículos de investigación empírica deben ser redactados según las normas vigentes de la American Psychological Association, APA (ver ejemplos señalados más abajo). Su estructura debe contemplar: introducción, método, resultados, discusión y referencias. Los trabajos que no cumplan con estas exigencias formales serán devueltos para ser corregidos.

6. Los artículos de investigación teórica pueden ser redactados según normas APA, o según las normas vigentes MLA Modern Language Association (ver estilos sugeridos más abajo a modo de ejemplo). Los trabajos que no cumplan con estas exigencias formales serán devueltos para ser corregidos.

7. Las figuras, imágenes, gráficos y tablas, deben venir incorporados en el texto. Las imágenes, gráficos y demás elementos, aunque vengan en color, se publicarán solamente en blanco y negro.

8. Las notas deben venir numeradas consecutivamente y ubicadas a pie de página, escritas en letra Times New Roman $n^{\circ}$ 10, párrafo justificado y espaciamiento doble.

Normas acerca de citas y referencias: algunos ejemplos ilustrativos.

I. Estilo según normas APA. Exigido estrictamente para artículos de investigación empírica.

1) Citas no textuales a modo de resumen o paráfrasis. Las formas pueden ser las siguientes:

Según Alvarez (1993), la violencia intrafamiliar supone siempre una relación fundada en la desigualdad de poder.

En 1988 Sternberg formuló una nueva aproximación al estudio de la inteligencia humana.

En los mecanismos de aprendizaje pueden distinguirse procesos tanto de asimilación como de acomodación (Piaget, 1980).

La idea general es que vayan señalados el autor y el año de la publicación que se está parafraseando o resumiendo.

2) Citas textuales. Si tienen menos de 40 palabras se utiliza la siguiente forma:

Los estudios exploratorios acerca del maltrato infantil "tienen utilidad solamente como aproximación fenomenológica a los determinantes subjetivos del victimario" (Hernández \& Salas, 1999, p. 20).

Si tienen más de 40 palabras, se omiten las comillas y se cita en texto aparte con un margen más amplio. 
El vínculo materno filial se torna así un espacio amenazante y persecutorio por definición. En este tipo de relaciones objetales:

El objeto aparece escindido e introyectado igualmente en tal condición, sin integración posible y con una carga paranoica, tan activa y poderosa, como lo es también la intensa necesidad sentida, todavía, de permanecer al cuidado y amparo de este mismo objeto. El vínculo con la madre se torna peligrosamente en un espacio relacional autoperpetuante. (Valladares, García \& Storadi, 1987, p. 79).

3) Citas de trabajos con más de un autor.

En caso de que existan dos autores, deben mencionarse los apellidos de ambos todas las veces que se cita la obra. Si se los menciona entre paréntesis, deben unirse con el signo \&. Si se los menciona en el cuerpo del texto, se los une con la letra " $y$ ". Ejemplos:

Los diseños cuasi-experimentales tendrían para este tipo de investigación una utilidad ciertamente limitada (Torres \& Araya, 1999).

Torres y Araya (1999) señalan que los diseños cuasi-experimentales tendrían para este tipo de investigación una utilidad ciertamente limitada.

Si se trata de entre 3 y 5 autores, se mencionan todos en la primera cita, y en las sucesivas sólo se menciona el apellido del primer autor (principal) seguido de la abreviación "et al.". Si se trata de 6 ó más autores, desde un inicio sólo se menciona el primer autor seguido de "et al.". Ejemplo:

Vargas, Cameron y Marías (2000) omiten en su categorización psicopatológica la presencia de rasgos antisociales.

Al comparar estas aproximaciones, Vargas et al. (2000) señalan que el componente antisocial queda entonces relegado únicamente al campo penal.

4) Referencias. En la lista de referencias, enumerada siempre al final del artículo, deben señalarse todas y solamente las fuentes utilizadas puntualmente para elaborar el artículo (no se mencionan lecturas, manuales o trabajos a modo de sugerencia al lector, ni como profundización ni como ampliación del tema). Se enumeran por orden alfabético de autor. Si se ha consultado más de un trabajo perteneciente a un mismo autor, deben ordenarse por fecha comenzando por la publicación más antigua. Si el autor aparece como autor principal en obras colectivas, debe comenzarse por las obras en las que aparece como autor individual. Las referencias que comparten los mismos dos o tres primeros autores, deben ordenarse alfabéticamente considerando al tercer o cuarto autor respectivamente.

Referencia de publicaciones periódicas (revistas, boletines, diarios).

Autor o autores (año). Título del artículo. Nombre de la revista, Volumen (número), páginas. Ejemplo:

Berstein, F., Fisher, G. \& McGove, J. (2002). Childhood and speech acts. Journal of social behavior, 21 (3), 99-115.

Referencia de publicación no periódica (libros).

Autor o autores (año). Título de la obra. Ubicación: Editorial. Ejemplo:

Grondona, P. (1977). La adolescencia: travesía de la identidad. Barcelona, España: Alta Vista.

Referencia de partes (capítulos) de libros, readings o compilaciones.

Autor o autores (año) Título del capítulo. En autor o autores editores/compiladores (Ed., o Comp.), Título del libro (páginas del capítulo). Ubicación: Editor. Ejemplo:

Fay, C. \& Hanson, B. (2003). Stress resistance and mental health. En W. Frege \& C. G. Denevue (Eds.), Mental health: Contemporary issues (pp. 211-234). New York, N.Y., EE.UU.: North Lincoln University Press.

Más información acerca de cómo citar y referir otras fuentes (conferencias, comunicaciones personales, entrevistas, páginas electrónicas, etc.), consultar en 1) www.apa.org, 2) www. apastyle.org/elecsource.html, o 3) http://owl.english.purdue.edu/handouts/research/r apa.htlm. 
II. Estilo según MLA. Especialmente sugerido para artículos de carácter teórico-reflexivo, ligados a las formas discursivas de las humanidades y la filosofía.

1) Citas textuales de libros en papel. Las citas en el texto, si son breves, deben ir entrecomilladas. Si son citas extensas (4 líneas o más) deben ir en renglón aparte, sin comillas y con márgenes adentrados.

Los datos a señalar para cada cita son: apellido del autor, página de donde se extrajo la cita, y título abreviado de la obra escrito en itálica, en caso de que se trabaje con más de una obra perteneciente al mismo autor. Al final de cada cita, entre paréntesis debe señalarse la información que no ha sido mencionada en el cuerpo del texto o párrafo. Es decir, si la cita se inserta sin haber mencionado al autor, entonces entre paréntesis se señala el apellido del autor y la página, o apellido, título abreviado de la obra y página, en caso de que se trabaje con más de una obra perteneciente a un mismo autor.

Ejemplo de cita textual breve cuando se está trabajando con una sola obra del autor:

Las formas de pensamiento "tendrían una sintaxis previa y fundante respecto de las formas del lenguaje natural" (Fodor 122).

Ejemplo de citas textuales breves cuando se está trabajando con más de una obra perteneciente al mismo autor:

Las formas de pensamiento "tendrían una sintaxis previa y fundante respecto de las formas del lenguaje natural" (Fodor, Cognición y lenguaje 122). Sin embargo, lo propiamente fundante del pensamiento respecto del lenguaje sería su "estatus representacional simbólico, donador de todo el espesor semántico que portan los conceptos" (Fodor, Panorámica de los conceptos 98).

Si el autor es mencionado en el cuerpo del texto, entonces entre paréntesis sólo se señalan los datos que restan para identificar sin equívocos la fuente de la cita.

Ejemplo de esta cita cuando se trabaja con una sola obra del autor:

Según Habermas, "el psicoanálisis pone en práctica una conjunción novedosa de estrategias tanto explicativas como hermenéuticas" (122).

Ejemplo de esta cita cuando se trabaja más de una obra perteneciente al mismo autor:

Según Habermas, "el psicoanálisis pone en práctica una conjunción novedosa de estrategias tanto explicativas como hermenéuticas" (Teoría y praxis 122).

Ejemplo de cita extensa (4 líneas o más):

La habitual conciencia de sí, especialmente en aquellos actos que llamamos morales, suele sucumbir ante una serie de sesgos:

No son solamente los espectadores de un acto quienes miden con frecuencia la moralidad o inmoralidad por sus consecuencias; no, el autor mismo lo hace. Pues los motivos y las intenciones rara vez son lo suficientemente claros y sencillos, y a veces incluso la memoria parece turbada por las consecuencias, de modo que atribuimos a su propia acción motivos falsos o hacemos de motivos no esenciales los esenciales.

(Nietzsche 85)

Estas normas se aplican de igual modo si se trata de un autor institucional o corporativo (ONU, UNESCO, etc.).

La idea general de esta forma es que se señale entre paréntesis sólo aquella información que no ha sido mencionada en el cuerpo del texto, y que el lector necesitaría en caso de requerir la fuente exacta.

2) Citas de fuentes en Internet. Se procede siguiendo los mismos criterios señalados para textos en papel, pero reemplazando la información de número de página por la expresión "en línea". Ejemplo:

La doctrina de las epistemes, y especialmente aquella que funda las formas discursivas de las ciencias humanas, sería probablemente una de las más débiles construcciones foucaultianas (Gutiérrez, en línea). 